\title{
Diagnóstico diferencial de doença de graves por cintilografia
}

Segatto, Laís Gombar; Ortiz, Emanuelle Toledo; Vilas, Eduardo

Rosito de; Pagliarini, Adriane Schio; Berdichevski, Eduardo Herz

\section{Resumo}

INTRODUÇÃO: Doença de Graves é uma doença autoimune de etiologia desconhecida, possivelmente multifatorial e com fatores genéticos, mais frequente no sexo feminino, que causa hipertireoidismo. A cintilografia é indicada para a avaliação morfo-funcional da glândula, muitas vezes complementando dados clínicos ou ultrassonográficos. São habitualmente identificados os dois lobos tireoideanos, ocasionalmente o istmo e raramente o lobo piramidal. Além da localização, dimensões e morfologia também é analisada a distribuição do radiofármaco pelo parênquima glandular, que é normalmente homogênea. OBJETIVO: Relatar um caso de doença de Graves em que o diagnóstico diferencial ocorreu através de cintilografia. MÉTODO: relato de caso. Relato de caso: paciente de 65 anos, com exames laboratoriais resultantes em T4 aumentado e TSH suprimido. Paciente nega uso de medicações para tireoide e ecografia prévia. Foi ministrado 200microcurie de 131 iodo para realizar cintilografia de tireoide. Na imagem fica evidente uma homogeneidade no brilho o que leva a indução pra a normalidade. Porém, a captação do rádio iodo em 24 horas foi de $60 \%$, apontando para doença de graves, considerando imagem homogênea entre os lobos e a captação aumentada (normal até 30\%). CONCLUSÃO: No diagnóstico diferencial devemos entender que as medidas de captação do iodo são diretamente proporcionais ao grau de função e síntese hormonal da 
glândula. O iodo é captado por transporte ativo pela tireóide (bomba de iodeto), sendo incorporado à tironina para a síntese de hormônios tireoideanos (T3 e T4). Assim, deve-se analisar a taxa de captação (nesse caso 60\%) antes de verificar a imagem. Já que o T4 está suprimido levando à alta captação em toda região lobular, para que não haja erro diagnóstico de normalidade. 